\title{
APSA Minority Fellows Selected
}

\section{5-96 APSA African American Fellows}

Three exceptional students were selected as the APSA's funded African American Graduate Fellows for 199596. They are: Nikol G. Alexander of Southern University; Antonio Brown of Loyola Marymount University; and Tamara Saduddin-Singh of the University of South Carolina.

Ten other talented African American students were selected as non-funded fellows. They are Charles E. Blaylock of Shaw University; Matthew T. Bradley of Northeastern Illinois University; Yvonne D. Eaton of San Francisco State University; Jerome Hamilton of Youngstown State University; Kalya Hamlett of Spelman College; Tiffany J. Herard of Cornell University; Lisa M. Jackson of Syracuse University; Jonathan Q. Morgan of the University of Virginia; Rovana J. Popoff of Columbia University; and Mitchell Ross of Rutgers University at Camden.
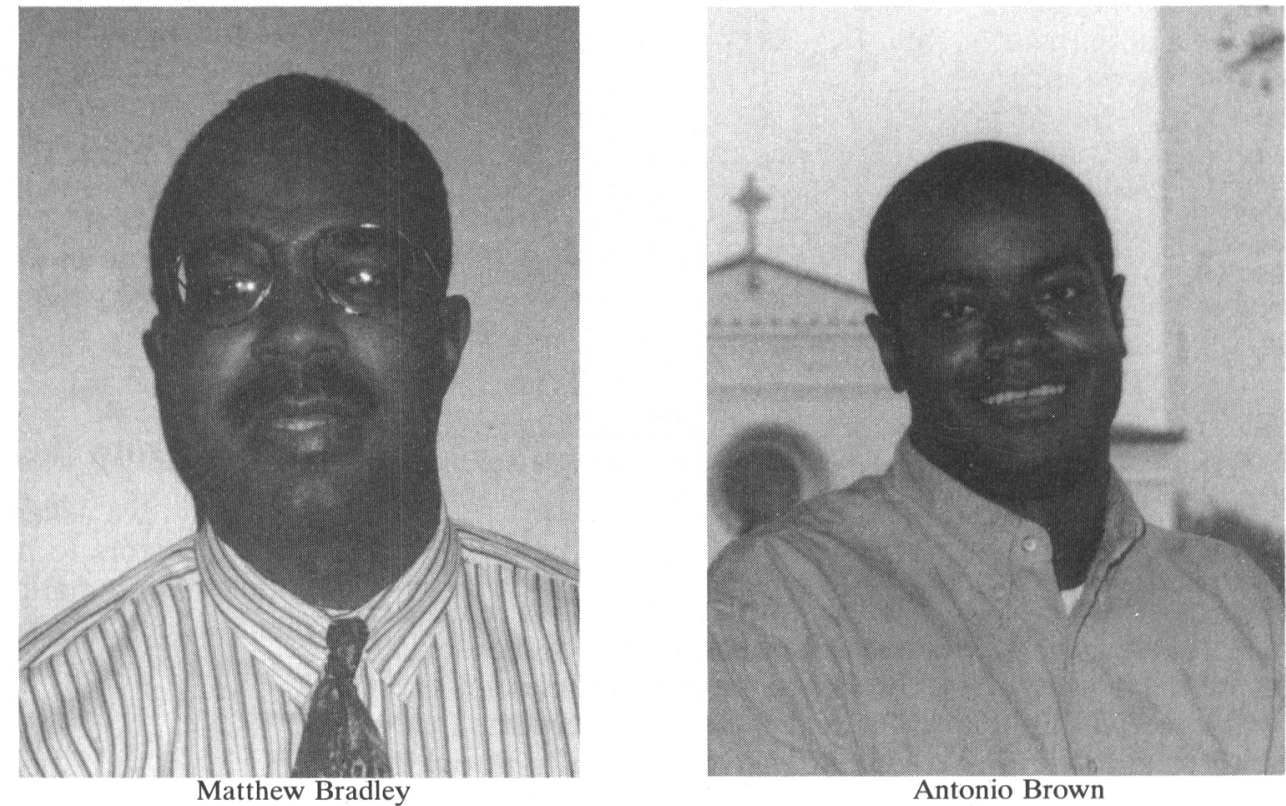

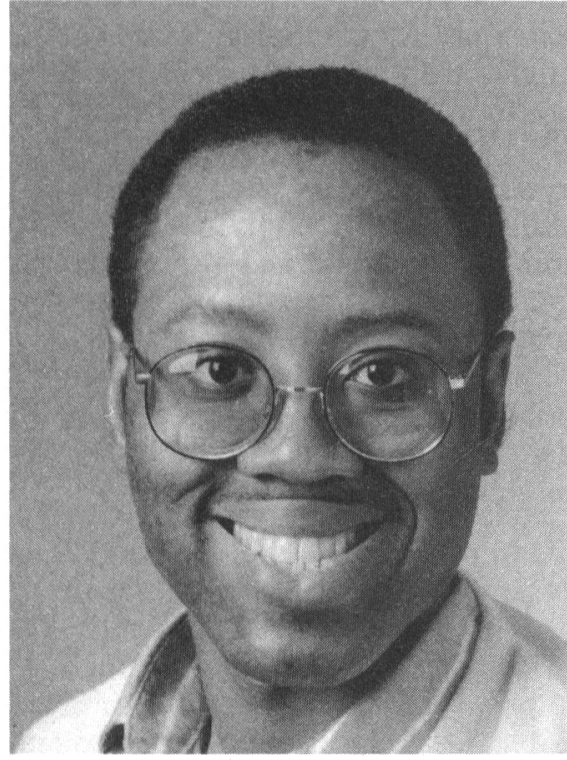

Jerome Hamilton

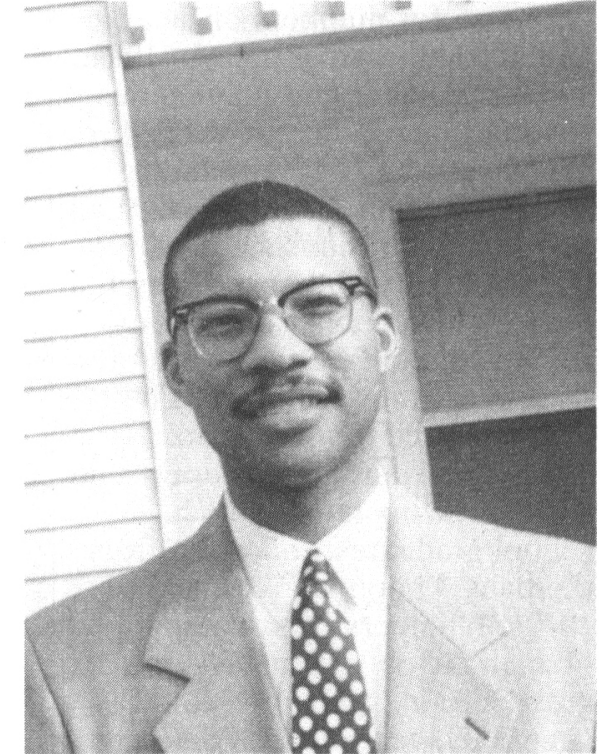

Jonathan Morgan

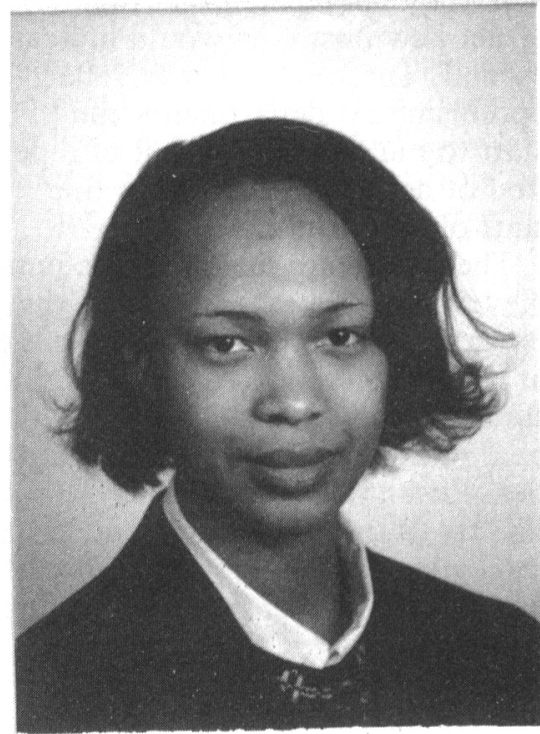

Tamara Sauddin-Singh 


\section{5-96 APSA Latino Graduate Fellows}

Sharon Ann Navarro was selected as the APSA's funded Latino(a) Graduate Fellow for 1995-96.

Four other excellent students were selected as non-funded Latino(a) Graduate Fellows. They are Viviana $M$. Abreu-Hernandez of the University of Puerto Rico; Vanna A. Gonzales of UCLA; Margot Olavarria of Hunter College; and Gabriella Rigg of Northeastern University.
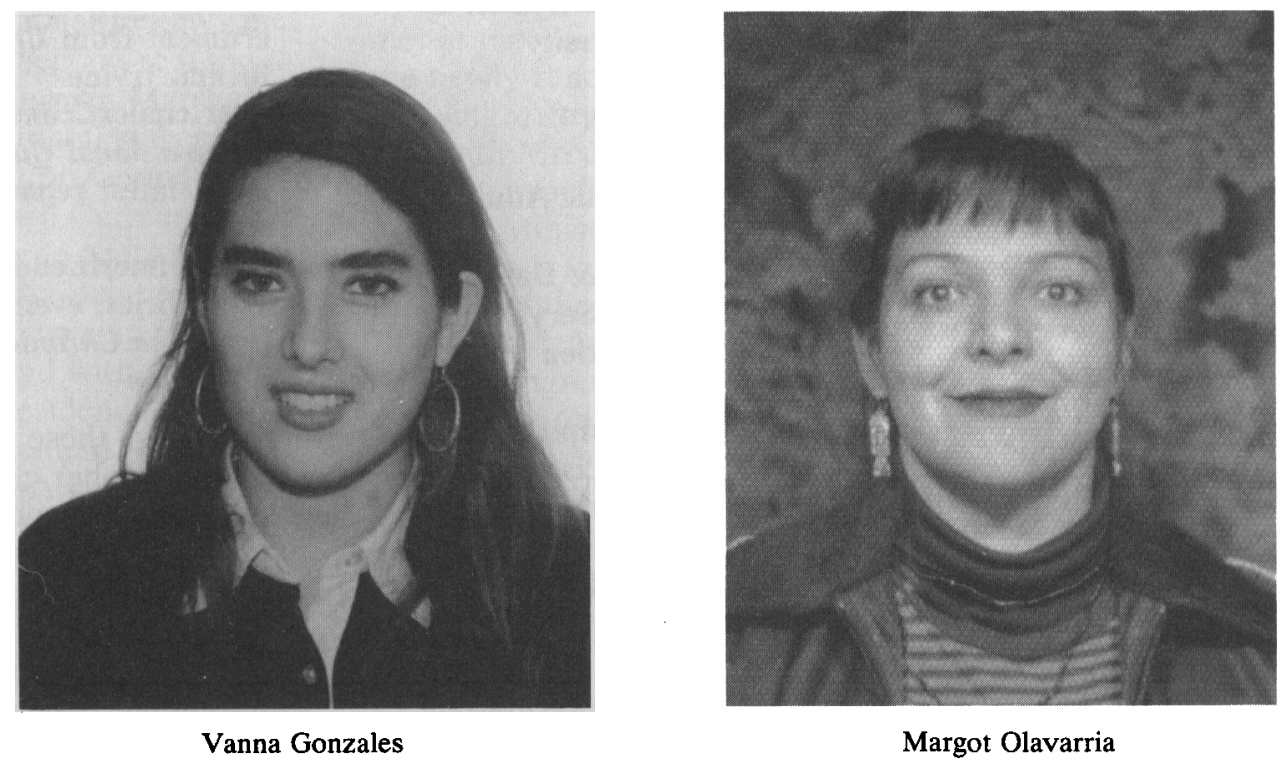

\section{APSA Offers Joint Memberships}

\section{Gabrielle Katz, $\boldsymbol{A P S A}$}

The American Political Science Association is pleased to be part of a developing arrangement with the American Sociological Association, the American Historical Association, and the American Society of International Law, to encourage inter-membership through special discounted rates. These joint memberships can significantly reduce the costs of participating in the scholarship of other disciplines.

The American Sociological Association is our largest affiliate. Founded in 1905, the ASA embodies a wide spectrum of people interested in advancing the scientific study of society. Membership benefits as an interdisciplinary associate member include a subscription to the newsletter, Footnotes, one journal of your choice (from a list of titles), and the Preliminary Annual Meeting Program. The discounted rate for APSA members to join the ASA is $\$ 46$.

The American Historical Association attempts to bring together scholars interested in all chronological, geographic, and topical specializations of history. Membership, at a special rate of $\$ 35$ for APSA members, includes the annual publications The American Historical Review and Perspectives, as well as the AHA Annual Meeting Program and other member discounts and benefits.

The newest interdisciplinary member is the American Society of International Law. Founded in 1906, the ASIL is a professional organization interested in the study and advancement of law in the international arena. The ASIL's diverse membership is comprised of lawyers and non-lawyers sharing a common interest in the promotion and continuance of law and policy as a basis for the study of international affairs. The $\$ 55$ membership for APSA members includes receipt of the premier quarterly in the field, The American Journal of International Law, and the ASIL Newsletter, published five times a year. Members enjoy interaction with over 4,500 worldwide members of ASIL involved in all aspects of international law, discounts on the annual meeting, the Hague meeting, and other society events and publications.

All of these scholarly societies are committed to joint membership opportunities to help scholars keep pace with the increasingly fluid interdisciplinary boundaries, recognizing that participants in different disciplines have common questions and common goals. Political science has always included a number of fields with cross-disciplinary roots, including political sociology, public opinion, political history, and political economy. This mutual exchange will allow scholars trained in other disciplines to stay current with the relevant cross-disciplinary work in political science.

If you are an APSA member interested in interdisciplinary mem- 